\title{
Web-based videoconferencing in online teaching during the COVID-19 pandemic: University students' perspectives
}

\author{
Stavros A. Nikou \\ School of Education \\ Faculty of Humanities and Social Sciences \\ University of Strathclyde \\ Glasgow, UK \\ stavros.nikou@strath.ac.uk
}

\begin{abstract}
Web-based videoconferencing systems have become very popular means of online teaching during the educational shift from face-to-face to online due to the COVID-19 pandemic. Students around the world have been attending online classes through different web-based videoconferencing platforms instead of face-to-face lectures and seminars. The current study aims to investigate University students' intentions to continue use webbased videoconferencing systems for their learning, when social distancing render unnecessary and Universities re-open after the pandemic is over. This study is part of our wider investigation on the impact of the COVID-19 pandemic on students' experiences about different e-learning technologies and related pedagogies. The current study proposes a model based on the Technology Acceptance Model (TAM) and the Expectancy Confirmation Model (ECM) in order to explain and predict continuance intention to use videoconferencing systems in the post-COVID-19 era. Sixty-one students from a School of Education in a UK University completed an online survey. Structural equation modelling was used to analyze the data. The model explains and predicts $53 \%$ of the total variance in continuance intention to use videoconferencing systems for learning online in terms of perceived usefulness, social influence, satisfaction and confirmation. Satisfaction and perceived usefulness were found to be the most significant predictors of continuance intention to use. Implications for the use of web-based videoconferencing systems for online teaching and learning in the post-COVID 19 landscape are discussed.
\end{abstract}

Keywords-continuous intention to use, web-based videoconferencing, online learning, Expectancy Confirmation Model, Technology Acceptance

\section{INTRODUCTION}

The COVID-19 global pandemic triggered a huge digital transformation in education worldwide. Schools and Universities around the world forced to shift their face-to-face classes to online. Various online technologies became mainstream offering great opportunities to cope with social distancing and school closures. This emergency shift of instructional delivery to online can be considered as a global "experimental setting" [1] offering opportunities to study online technologies and pedagogical practices for utilisation not only during the lockdown but in the post-pandemic landscape as well. One of these online technologies is web-based videoconferencing; students around the globe were encouraged and/or forced to use videoconferencing systems (e.g. Zoom, Microsoft Teams, Google Hangouts, etc.) for their classes instead of the traditional face-to-face lectures, seminars and other learning episodes.

In this context, the current study seeks to investigate University students' continuance intention to use web-based videoconferencing not only during but also after the lockdown restrictions. An important factor for the successful implementation of any information system is users' adoption and their intention to continue using it. Determining the factors that affect students' continuance intention to use web-based videoconferencing, can help to better integrate this technology in future e-learning practices. To our knowledge, this is one of the first attempts to model students' attitudes towards continuous intention to use videoconferencing for teaching purposes. This specific study is part of our wider investigation on the impact of the COVID-19 pandemic on students' perceptions about e-learning.

Technology acceptance [2] and expectation confirmation theory [3] following next, provide the theoretical background for this study. The proposed model and our hypotheses come afterwards. Methodology, data analysis and results sections follow. The paper concludes with discussions including limitations and future research. 


\section{BACKGROUND}

\section{A. Technology Acceptance Model (TAM)}

Technology Acceptance Model (TAM) [2] is a standard and widely accepted theory to model user acceptance of technology. To explain and predict behavioural intention to use a technology, the constructs of perceived usefulness, perceived ease of use and attitudes towards usage have been introduced [2]. Perceived usefulness has been defined as the "degree to which a person believes that using a particular system will enhance his/her job performance" (p.320) [2] and perceived ease of use has been defined as "the degree to which a person believes that using the system would be free of effort" (p. 320) [2]. Perceived usefulness, perceived ease of use and attitude towards use influence behavioural intention to use information systems. Different variables have been added to the model since its first introduction. Social influence, the "degree to which an individual perceives that important others believe he or she should use the new system" (p.451) [4] is one of them. The model has been successfully applied on a wide spectrum of elearning systems [5]. A few studies also exist on the acceptance of videoconferencing systems confirming the aforementioned links between the variables of the model [6], [7].

\section{B. Expectation Confirmation Model (ECM)}

The Expectation Confirmation Model (ECM) [3] explains and predicts continuous intention to use information systems based on the constructs of perceived usefulness, confirmation and satisfaction. Confirmation is the degree to which users' original expectations before using the system are confirmed after using the system [3]. Satisfaction is the psychological or affective state related to or resulting from confirmation [3]. Previous research on e-learning provided evidence that perceived usefulness, confirmation and satisfaction are significant determinants of continuance intention to use [8]. While the impact of social influence on continuance intention to use has been studied in different e-learning environments [9], limited research exists about the impact of social influence on learning technologies such as videoconferencing. Moreover, no studies exist so far to investigate students' continuance intention to use web-based videoconferencing for attending online lectures and participating in online seminars after the COVID19 crisis.

\section{III.RESEARCH FRAMEWORK AND HYPOTHESES}

The current research framework utilizes the expectation confirmation model [3] along with constructs from the technology acceptance model [2] in order to explain and predict continuance intention to use web-based videoconferencing in online education settings after the COVID-19 crisis, when online teaching will not be the only choice. Perceived usefulness and social influence from the technology acceptance research [2], [4] are combined with satisfaction, confidence and continuance intention to use from the continuance research [3].The following hypotheses have been developed:

\section{Social Influence}

Previous research provided evidence for the positive impact of social influence on behavioural intention to use through the constructs of perceived usefulness and perceived ease of use [10]. Moreover, social influence can be an important predictor of continuous intention to use e-learning systems [9]. Similarly, in our model we hypothesize that students' perceptions that important others think they should use web-based videoconferencing during online learning can positively influence their intention to continue use this technology. Therefore:

H1. Social Influence (SI) has a positive effect on Continuous Intention to Use (CIU).

\section{Perceived Usefulness}

Perceived usefulness of an information system is positively associated with their satisfaction and continuance intention to use IS [3]. Studies have shown that when users find the system useful they are satisfied by using it and are willing to continue use it [11], [12]. Similarly, we hypothesize that students who perceive web-based videoconferencing as useful for their learning can be satisfied with the system as well. Therefore:

H2. Perceived Usefulness (PU) has a positive effect on Satisfaction (SAT).

\section{Confirmation}

Expectancy confirmation theory posits that confirmation of expectations that follow the actual system use is positively associated with user satisfaction and perceived usefulness [3]. Studies in online environments such as MOOCs [13] and other web-based learning systems [14] have confirmed this association. We also hypothesise that when students' expectations from using the web-based videoconferencing system have been confirmed, their satisfaction with the system and their perceived levels of the system usefulness can positively influenced. The following hypotheses have been made:

H3. Confirmation (CONF) has a positive effect on Satisfaction (SAT).

H4. Confirmation (CONF) has a positive effect on Perceived Usefulness (PU).

\section{Satisfaction}

Previous studies have shown that satisfaction has the most significant effect on users' intention to continue use information systems [14]. High levels of satisfaction can lead stronger intentions to continue use MOOCs [13] and e-learning systems [15]. Therefore, we can also hypothesize for web-based videoconferencing that:

H5. Satisfaction (SAT) has a positive effect on Continuous Intention to Use (CIU). 


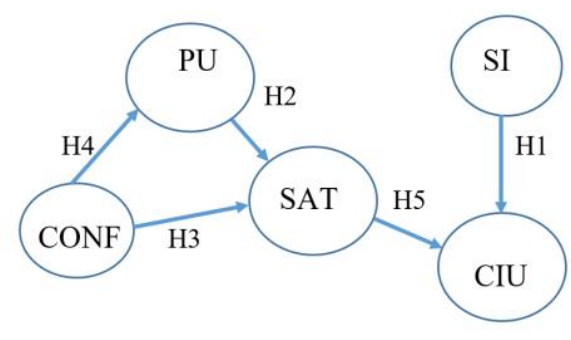

Fig. 1. The proposed model for web-based video-conferencing CIU

\section{IV.METHODOLOGY}

\section{a. Participants and Procedures}

Participants in this research study were 61 undergraduate students from a School of Education in the UK. There were 47 females (77\%) and 14 males (23\%). The average age of the students was $21.7(\mathrm{SD}=3.4)$. Participants' information sheets informed students in advance about the research procedure, participation was voluntary and informed consent obtained. Students were asked to complete a fully anonymous online questionnaire about their intentions to continue use web-based videoconferencing systems for attending lectures and seminars and participating in online workshops when the social restrictions render unnecessary after the COVID-19 pandemic. The online questionnaire became available to the participating students through the University online survey software.

\section{b. Instrumentss}

In order to evaluate the perceived levels of Continuance Intention to Use and the influencing factors we have used items from previously validated instruments. For Continuance Intention to Use (CIU) and Confirmation (CONF) we adopted items from [3]. For Satisfaction (S) we adopted items from [16]. Social Influence (SI) was measured according to the scale developed by [4]. Perceived Usefulness (PU) was measured according to the scale developed by [2]. Participants answered a seven-point Likert-scale ranging from 1 (not at all true) to 7 (very true). Appendix presents the 13 items questionnaire used in the study.

\section{DATA ANALYSIS}

Partial Least-Squares (PLS) with Smart PLS 2.0 [17] was used for the data analysis in order to predict the factors that influence Continuous Intention to Use web-based video conferencing for educational purposes. The choice of using PLS-SEM was made due to its high predictive power and the small sample size of our study. Our data sample size satisfies the conditions imposed by [18] and exceeds the recommended value of 20 e.g. 10 times the largest number of independent variables influencing a depended variable [18].

The quality of the model has been ensured by verifying the internal consistency, convergent and discriminant validity of the proposed model. All criteria for convergent validity are satisfied: all factor loadings on their relative construct exceed 0.70 , composite reliability of each construct is greater than 0.70 and all average variance extracted (AVE) values exceed the variance due to measurement error for that construct, being in the range from 0.701 to 0.829 (AVE > 0.50) (Table I).
Discriminant validity criterion is also satisfied since the square root of the average variance extracted (AVE) of a construct is higher than any correlation with another construct (Table II). Therefore both convergent and discriminant validity for the proposed research model are verified [19].

The results from the PLS analysis support all our five hypotheses. A bootstrapping procedure has been applied to measure the t-values and the variance measured (R2) by the antecedent constructs. All hypotheses of the structural model have been supported by the value and the significance of the path coefficients. Table III summarizes the structural model and the hypotheses testing results by showing the statistical significance of the relations in the model. Figure 2 shows the path coefficient for each path and the $\mathrm{R}^{2}$ for each endogenous variable. All standardized path coefficients have values between 0.215 and 0.660 . These values are considered to be medium to large [20].

Confirmation significantly predicts Perceived Usefulness (0.471) and student Satisfaction (0.283). Confirmation of student expectations by using the web-based videoconferencing system strengthen student perceptions about the usefulness of the system and ultimately student satisfaction. Perceived Usefulness also significantly predicts student Satisfaction $(0.660)$. Students are more satisfied by using the videoconferencing system if they perceive it as useful. Satisfaction has a significant influence on Continuance Intention to Use $(0.590)$. When students are satisfied by using the web-based videoconferencing system, they are more likely to continue using it.

TABLE I. DESCRIPTIVE STATISTICS AND RESULTS FOR CONVERGENT VALIDITY FOR THE MEASUREMENT MODEL

\begin{tabular}{lccccc}
\hline \multicolumn{1}{c}{$\begin{array}{c}\text { Construct } \\
\text { Items }\end{array}$} & $\begin{array}{c}\text { Mean } \\
\text { (SD) }\end{array}$ & $\begin{array}{c}\text { Factor } \\
\text { Loading }\end{array}$ & $\begin{array}{c}\text { Cronbach's } \\
\mathbf{a}\end{array}$ & $\begin{array}{c}\text { Composite } \\
\text { Reliability }\end{array}$ & AVE \\
\hline $\begin{array}{l}\text { Social } \\
\text { Influence }\end{array}$ & & 0.795 & 0.907 & 0.829 \\
SI1 & 0.896 & & & \\
SI2 & 0.925 & & & \\
\hline
\end{tabular}

\begin{tabular}{lllll}
\hline Confirmation & 0.895 & 0.649 & 0.849 & 0.738 \\
CONF1 & 0.821 & & & \\
CONF2 & & 0.801 & 0.883 & 0.715 \\
\hline Perceived & 0.824 & & & \\
Usefulness & 0.844 & & & \\
PU1 & 0.868 & & 0.701 \\
PU2 & & & & \\
PU3 & 0.875 & & \\
\hline Satisfaction & & & & \\
SAT1 & 0.866 & & & \\
SAT2 & 0.823 & & 0.739 \\
SAT3 & 0.889 & & & \\
\hline Continuous & & & & \\
Intention to & & & & \\
Use & & & & \\
CIU1 & & & & \\
\hline
\end{tabular}




\begin{tabular}{lccccc}
\hline $\begin{array}{c}\text { Construct } \\
\text { Items }\end{array}$ & $\begin{array}{c}\text { Mean } \\
\text { (SD) }\end{array}$ & $\begin{array}{c}\text { Factor } \\
\text { Loading }\end{array}$ & $\begin{array}{c}\text { Cronbach's } \\
\mathbf{a}\end{array}$ & $\begin{array}{c}\text { Composite } \\
\text { Reliability }\end{array}$ & AVE \\
\hline CIU2 & & 0.807 & & \\
CIU3 & & 0.881 & & \\
\hline
\end{tabular}

TABLE II. DISCRIMINANT VALIDITY FOR THE MEASUREMENT MODEL

\begin{tabular}{cccccc} 
& CIU & CONF & PU & SAT & SI \\
\hline CIU & $\mathbf{0 . 8 6 0}$ & & & & \\
CONF & 0.471 & $\mathbf{0 . 8 5 9}$ & & & \\
PU & 0.594 & 0.471 & $\mathbf{0 . 8 4 6}$ & & \\
SAT & 0.708 & 0.594 & 0.794 & $\mathbf{0 . 8 3 7}$ & \\
SI & 0.540 & 0.427 & 0.414 & 0.552 & $\mathbf{0 . 9 1 1}$ \\
\hline \multicolumn{5}{c}{ CIU: Contiguous Intention to Use, CONF: Confirmation, PU: Perceived Usefulness, } \\
& \multicolumn{4}{c}{ SAT: Satisfaction, SI: Social Influence }
\end{tabular}

Social influence has also a significant effect on the Continuance Intention to Use the system $(0.215)$ because if students are influenced by their social environment to continue use the system, they are more likely to continue use it. The path coefficients found in our study are comparable with path coefficient found in other studies as well [21].

TABEL III. HYPOPTHESES TESTING RESULTS

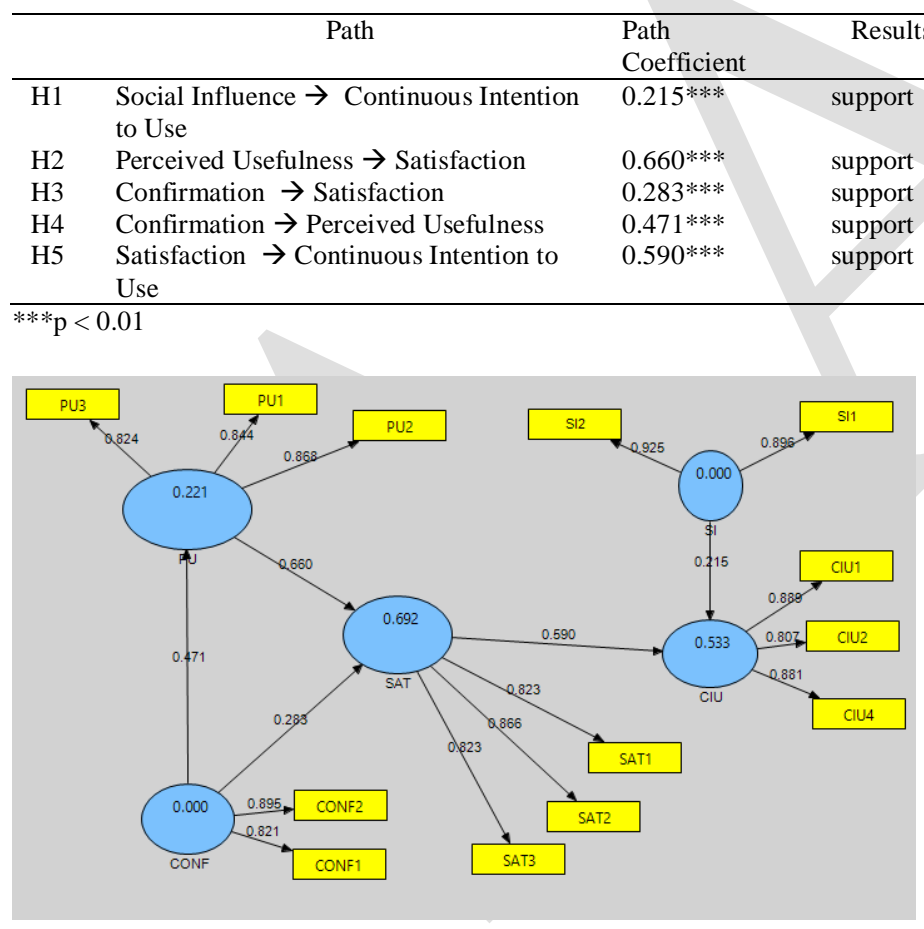

Fig. 2. SEM analysis of the proposed model

\section{DISCUSSIONS AND CONCLUSIONS}

The purpose of the current study is to identify the significant determinants that influence University students' intention to continue use web-based videoconferencing systems for learning. The specific study is part of our wider investigation on the impact of the COVID-19 pandemic on students' experience on different e-learning technologies and related pedagogies.

The forced shift of education from face-to-face to online due to the pandemic, raised opportunities for many online technologies to be utilised during the lockdown and also supported the educational community to cope with the social distancing. Despite the fact that emergency remote teaching is different from purposefully designed e-learning, online learning experiences gained during the pandemic can further empower technology-enhanced learning. Web-based videoconferencing became a mainstream online technology that replaced in-person teaching in schools worldwide. Looking ahead in the postCOVID era, when social distancing render unnecessary and Universities re-open after the pandemic is over, web-based videoconferencing can still play an important role in the context of digital transformation in education that has already started [22].

The current study provides evidence that University students' continuance intention to use web-based videoconferencing for learning depends on satisfaction, perceived usefulness, confirmation and social influence. Satisfaction and perceived usefulness were found to be the most significant predictors. Students will continue using the system if they are satisfied with it and they perceive it as useful. The findings of the current study are in agreement with previous research on technology acceptance [2], [4], expectation confirmation theory [3] and they are also in agreement with recent studies on other e-learning systems [15], [21], [11].

Disconfirmation of students' expectations can have a negative impact on their intention to continue use [24]. Students' dissatisfaction or the feeling of disappointment from using the system can also have a negative influence. Our findings show that social influence is another factor that needs to be considered when engage with videoconferencing for learning. The impact of social factors on continuance intention to use is rather underrepresented in the related literature [24].

To the best of our knowledge, the current study is one of the first to investigate post-adoption of web-based videoconferencing for teaching during and after the pandemic. Users' values, attitudes and mind-sets are among the main factors that can contribute to digital transformations. Our study findings on students' intentions may help instructional practices and course design. It might be the case that students have usually little agency on selecting the information technology platform or mode of instruction. However, taking into consideration students' intentions and especially the technology they use for their own learning, it would be helpful for instructional designers and teachers to design and deliver engaging learning interventions.

Specific aspects of this technology can affect users' continuances intention in a particular way and this is a topic that needs to be further investigated. How students perceive the different features that web-based video conferencing systems offer? How these features can leverage online teaching?

The study has limitations. One limitation might be considered the general criticism of the TAM model [25]. The main study limitation is on the socio-demographic factors. 
Different student groups may have different motivations to continue using a technology [26]. Ongoing study aims to engage more students from a variety of backgrounds and educational contexts and investigate how students perceive the different features and capabilities of web-based videoconferencing systems.

\section{ACKNOWLEDGMENT}

Authors would like to thank the students who participated in the research.

\section{REFERENCES}

[1] C. Giovannella, "Effect induced by the Covid-19 pandemic on students' perception about technologies and distance learning", SLERD 2020 - 5th conference on Smart Learning Ecosystems and Regional Development, Online, 29-30 June 2020.

[2] F.D. Davis, "Perceived usefulness, perceived ease of use and user acceptance of information technology". MIS Quartely, vol.13, no.3, pp. 319-340, 1989.

[3] A. Bhattacherjee, "Videoconferencing for qualitative Data collection: perceptions and experiences of researchers and participants", International Journal of Qualitative Methods, vol. 18, pp. 1-8, 2001.

[4] V. Venkatesh, M.G. Morris, G.B. Davis, and F.D. Davis, "User acceptance of information technology: Toward a unified view", MIS Quarterly, vol. 27, no. 3, pp. 425-478, 2003.

[5] B. Sumak, M. Hericko, and M. Pusnik, "A meta-analysis of e-learning technology acceptance: The role of user types and e-learning technology types", Computers in Human Behavior, vol. 27, pp. 2067-2077, 2011.

[6] B. Fallery, R. Taddei, and S. Sylvie Gerbaix, "Acceptance and Appropriation of Videoconferencing for E-training: An Empirical Investigation", International Journal of Technology and Human Interaction, vol. 6, no. 3, pp. 1-16, 2010.

[7] S. Lakhal, H. Khechine, and D. Pascot, "Student behavioural intentions to use desktop video conferencing in a distance course: integration of autonomy to the UTAUT model", Journal of Computing in Higher Education, vol. 25, no. 93-121, 2013.

[8] G. Dağhan and B. Akkoyunlu, "Modeling the continuance usage intention of online learning environments", Computers in Human Behavior, vol. 60, pp. 198-211, 2016.

[9] L. Kaewkitipong, C.C. Chen, and P. Ractham, "Using social media to enrich information systems field trip experiences: Students' satisfaction and continuance intentions", Computers in Human Behavior, vol. 63, pp. 256-263, 2016.

[10] F. Abdullah and R. Ward, "Developing a general extended technology acceptance model for E-learning (GETAMEL) by analysing commonly used external factors", Computers in Human Behavior, vol. 56, pp. 238$256,2016$.

\begin{tabular}{|c|c|c|}
\hline Items & Questions & Sources \\
\hline \multicolumn{3}{|c|}{ Perceived Usefulness } \\
\hline PU1 & $\begin{array}{l}\text { Using the system will improve my } \\
\text { work. }\end{array}$ & Davis (1989) \\
\hline PU2 & $\begin{array}{l}\text { Using the system will enhance my } \\
\text { learning. }\end{array}$ & \\
\hline PU3 & $\begin{array}{l}\text { Using the system will increase my } \\
\text { productivity. }\end{array}$ & \\
\hline \multicolumn{3}{|c|}{ Social Influence } \\
\hline SI1 & $\begin{array}{l}\text { The seniors in my university have } \\
\text { been helpful in the use of the } \\
\text { system. }\end{array}$ & $\begin{array}{l}\text { Venkatesh et } \\
\text { al. (2003) }\end{array}$ \\
\hline SI2 & $\begin{array}{l}\text { In general, my university has } \\
\text { supported the use of the system. }\end{array}$ & \\
\hline
\end{tabular}

[11] I. Rodríguez-Ardura and A. Meseguer-Artola, "What leads people to keep on e-learning? An empirical analysis of users' experiences and their effects on continuance intention", Interactive Learning Environments, vol. 24, no. 6, pp. 1030-1053, 2016.

[12] J.C. Roca and M. Gagné, "Understanding e-learning continuance intention in the workplace: A self-determination theory perspective", Computers in Human Behavior, vol. 24, no.4, pp. 1585-1604, 2008.

[13] A.A, Daneji, A. F. M. Ayub, and M.N.M. Khambari, "The effects of perceived usefulness, confirmation and satisfaction on continuance intention in using massive open online course (MOOC)", Knowledge Management \& E-Learning, vol. 11, no. 2, pp. 201-214, 2019.

[14] M. Lee, "Explaining and predicting users' continuance intention toward e-learning: an extension of the expectation-confirmation model". Computers \& Education, vol. 54, no. 2, pp. 506-516, 2010.

[15] W. S. Lin, and C.H. Wang, "Antecedences to continued intentions of adopting e-learning system in blended learning instruction: a contingency framework based on models of information system success and tasktechnology fit", Computers \& Education, vol. 58, no.1, pp. 88-99, 2012.

[16] C.S. Lin, S. Wu, and R.J.Tsai, "Integrated perceived playfulness into expectation-confirmation model for web portal context", Information Management, vol. 42, no. 5, pp. 683-693, 2005.

[17] C.M. Ringle, S. Wende, and A. Will, SmartPLS 2.0 [computer software], Retrieved from http://www.smartpls.com

[18] W.W. Chin, "The partial least squares approach to structural equation modeling. In G. A. Marcoulides (Ed.)". Modern business research methods (pp.2 95-336). Mahwah, NJ: Lawrence Erlbaum Associates, 1998.

[19] J.F. Hair, G.T.M. Hult, C.M. Ringle, and M. Sarstedt, "A primer on partial Least squares structural equation modeling (PLS-SEM)", Thousand Oaks: Sage, 2014.

[20] J. Cohen, "Statistical power analysis for the behavioral sciences (2nd ed.)", Hillsdale, NJ: Erlbaum, 1988.

[21] MN.A. Rahman, S.N.A. Zamri, and L.K. Eu, "A meta-analysis study of satisfaction and continuance intention to use educational technology". International Journal of Academic Research in Business and Social Sciences, vol.7, no.4, pp.1059-1072, 2017.

[22] G. Fletcher and M. Griffiths, "Digital transformation during a lockdown, International Journal of Information Management”, vol. 55, 102185, 2020.

[23] G. Vial, "Understanding digital transformation: A review and a research agenda", The Journal of Strategic Information Systems, 2019.

[24] M. Yan, R. Filieri, and M. Gorton, , "Continuance intention of online technologies: A systematic literature review", International Journal of Information Management, vol. 58, 102315, 2021.

[25] R.P. Bagozzi, "The Legacy of the Technology Acceptance Model and a Proposal for a Paradigm Shift", Journal of the Association for Information Systems, vol. 8, no. 4, 12, 2007.

[26] S.A. Nikou, "Web-based videoconferencing for teaching online: Continuance intention to use in the post-COVID-19 period", Interaction Design and Architecture(s) Journal - IxD\&A, no. 47, pp.123 - 143, 2021. 


\begin{tabular}{|c|c|c|}
\hline \multicolumn{3}{|c|}{ Satisfaction } \\
\hline SAT1 & $\begin{array}{l}\text { I am satisfied with the use of the } \\
\text { system. }\end{array}$ & $\begin{array}{l}\text { Lin et al. } \\
(2005)\end{array}$ \\
\hline SAT2 & $\begin{array}{l}\text { I am pleased with the experience of } \\
\text { using the system. }\end{array}$ & \\
\hline SAT3 & $\begin{array}{l}\text { My decision to use the system was } \\
\text { a wise one. }\end{array}$ & \\
\hline \multicolumn{3}{|c|}{ Confirmation } \\
\hline CONF1 & $\begin{array}{l}\text { My experience with using the } \\
\text { system was better than what I } \\
\text { expected. }\end{array}$ & $\begin{array}{l}\text { Bhattacherjee } \\
\text { (2001) }\end{array}$ \\
\hline CONF2 & $\begin{array}{l}\text { The functionalities provided by the } \\
\text { system were better than what I } \\
\text { expected. }\end{array}$ & \\
\hline \multicolumn{3}{|c|}{ Continuance Intention to Use } \\
\hline CIU1 & $\begin{array}{l}\text { My intentions are to continue using } \\
\text { the system. }\end{array}$ & $\begin{array}{l}\text { Bhattacherjee } \\
\text { (2001) }\end{array}$ \\
\hline CIU2 & $\begin{array}{l}\text { I will continue using the system in } \\
\text { the future. }\end{array}$ & \\
\hline CIU3 & $\begin{array}{l}\text { I intend to continue using the } \\
\text { system rather than discontinue its } \\
\text { use. }\end{array}$ & \\
\hline
\end{tabular}

